\title{
PROTON-PUMP INHIBITOR USE AND POTENTIAL DRUG INTERACTIONS IN OUTPATIENTS
}

\author{
NADIA FARHANAH SYAFHAN ${ }^{1 *}$, MAULIDYA AUGUSTINE ${ }^{1}$, UCI RAMADHANI ${ }^{1}$, YETTI HERSUNARYATI ${ }^{2}$
}

${ }^{1}$ Department of Pharmacy, Faculty of Pharmacy, Universitas Indonesia, Depok, 16424, Indonesia. ${ }^{2}$ Pharmacy Installation of Gatot Soebroto Army Hospital, Jakarta, 10410, Indonesia. Email: nadia.farhanah@farmasi.ui.ac.id

Received: 04 April 2018, Revised and Accepted: 22 October 2018 and 01 November 2018

ABSTRACT

Objective: This study aimed to evaluate the use and potential drug interactions of proton-pump inhibitor (PPI) in outpatients.

Methods: This study is a retrospective descriptive analysis of prescriptions and medical records from outpatients in Gatot Soebroto Army Hospital selected by purposive sampling who received PPI with one or more other drugs from July to December 2015 . The analysis was conducted on 400 prescriptions from 192 patients.

Results: Data showed that $100 \%$ of the PPI therapy utilized was appropriate for the patients' condition, $79.00 \%$ was appropriate for the indication, $79.00 \%$ was appropriate for the dosage, $79.00 \%$ had an appropriate administration duration, and $83.75 \%$ was given the appropriate drug. The potential of PPI interactions with other drugs was found in 324 prescriptions $(81.00 \%)$ from 475 cases. Of all the cases, 42 were considered major interactions, 138 were moderate interactions, and 295 cases had minor interactions. There were 14 drugs that could potentially interact with PPI, such as mycophenolate mofetil, clopidogrel, cilostazol, warfarin, iron, levothyroxine, propranolol, cyclosporine, simvastatin, atorvastatin, cyanocobalamin, sucralfate, theophylline, and antacids.

Conclusion: PPI use in outpatients at the Gatot Soebroto Army Hospital was not entirely appropriate and had a large number of potential drug interactions with concurrent drugs.

Keywords: Drug interaction, Drug use, Outpatients, Proton-pump inhibitor

(C) 2018 The Authors. Published by Innovare Academic Sciences Pvt Ltd. This is an open access article under the CC BY license (http://creativecommons. org/licenses/by/4. 0/) DOI: http://dx.doi.org/10.22159/ijap.2018.v10s1.79

\section{INTRODUCTION}

Since their discovery in 1989, proton-pump inhibitors (PPIs) have been widely used for the treatment of various gastric acid-related disorders. In the case of gastrointestinal (GI) diseases, PPI is preferred because of their high success rate as a treatment. PPI use has increased by $456 \%$ since the 1990 s, suggesting that PPI has become one of the most commonly prescribed drugs in the world [1]. In 2009, PPI was the third highest prescribed drug in the United States with 119.4 million prescriptions [2]. In Australia, PPI was in the top ten of the highest prescribed medications in 2013.

Several clinical trials have shown that PPI is safe and well tolerated when used appropriately; however, excessive use and increased drug abuse may result in increased side effects [1]. Sheen and Triadafilopoulos showed that $75 \%$ of long-term PPI users of 60-89 years old experienced Vitamin B12 deficiency as a side effect of the antiviral drug [3]. Van der Hoorn et al. agreed that there was an increased risk of fractures due to osteoporosis associated with long-term use of PPI [4].

PPI have often been used in conjunction with other classes of drugs because of their extensive use, thus increasing the potential for drug interactions. According to Setiawati, the level of polypharmacy has influenced the potential for drug interactions [5]. The potential of drugs interactions can increase when the consumption of the drugs higher. However, not all potential interactions that occurred were clinically meaningful interactions [5]. The clinical significance of a drug interaction can be seen from its severity as a minor, moderate, or major interaction [6].

This study aimed to evaluate the use of PPI at Gatot Soebroto Army Hospital in Jakarta, Indonesia, based on assessment of the patient's condition, indications, dosage, administration duration, and drug selection, as well as a description the potential drug interaction of PPI to increase the alertness of health workers to the adverse effects of drug interactions.

\section{METHODS}

This research was a retrospective descriptive analysis and was conducted in a pharmacy installation and the medical record room of Gatot Soebroto Army Hospital in Central Jakarta from February to April 2016. The data used were secondary data taken from the prescriptions and medical records of outpatients from July to December 2015. Purposive sampling was used to choose the subjects, and the data include all Social Insurance Administration Organization outpatients from July to December 2015 who received PPI with one or more other drugs.

The evaluation of the use of PPI was based on an appropriate assessment of the patients' condition, indications, dosage, administration duration, and drug selection by comparing the data obtained from the Drug Information Handbook, $17^{\text {th }}$ edition, Pharmacotherapy: A Pathophysiologic Approach, $6^{\text {th }}$ Edition, Informasi Obat Nasional Indonesia 2014, and related journals. The potential drug interactions of PPI were traced electronically using Micromedex Solutions (2016, Truven Health Analytics, Inc., Ann Arbor, MI) and traced manually based on Stockley's Drug Interaction $8^{\text {th }}$ edition, Drug Interactions by Hansten, Drug Interaction Facts, $5^{\text {th }}$ edition, and related journals.

Microsoft Excel (2010) was used to perform a univariate analysis. This analysis aimed to explain the characteristics of research variables through the frequency and percentage of the occurrence of each variable including the distribution of patient characteristics sex, age, diagnosis, and description of PPI therapy that consist of classes of PPI, dosage regimen, and administration duration, evaluation of the rational use of PPI (assessment of the patient's condition, indication of disease, dosage, administration duration, and drug selection), and potential drug interactions of PPI with other drugs. 


\section{RESULTS AND DISCUSSION}

\section{Patient characteristics}

The number of female patients was higher than men; the data included 126 female patients (65.63\%) and 66 male patients (34.38\%) (Table 1). Women tended to maintain their weight and had an ideal body mass index by adjusting their dietary habits or diet. Regulated eating habits are crucial for gastric-acid secretion because these conditions allow the stomach to recognize feeding time so the stomach acid production can be controlled. This is the opposite of what occurs when a patient has an eating disorder where the production of stomach acid is excessive and irritates the mucosal wall of the stomach, which eventually causes nausea and pain.

Most of the patients who received PPI were over 65 years of age ( 89 patients; $46.35 \%$ ). The aging process reduces the capacity of the gastric mucosa to protect against damage. This change was evident from the failure of the gastric mucosal barrier and increased risk of gastric and duodenal ulcers in the elderly, which was primarily due to nonsteroid anti-inflammation drug (NSAID) such as sodium diclofenac SAID. In addition, this change increased the incidence of gastric and duodenal ulcers in the elderly, induced by Helicobacter pylori [8]

PPI was most widely used for the treatment of diabetes mellitus (DM) type 2 (153 cases; $38.52 \%$ ). DM type 2 was not the appropriate main indication for the use of PPI; however, DM is a systemic disease that could lead to dysfunction of various organs and impaired GI function. These problems were often encountered in patients with DM. Patients with diabetes often complain of the symptoms of upper GI disorders without any apparent cause. Particular tests could show a delay in emptying the stomach or diabetic gastroparesis, which commonly occur in people with DM types 1 and 2 [9]. Gastroparesis itself has been defined as the delayed emptying of the stomach characterized by a rapidly satiated, full feeling in the stomach, nausea, vomiting, bloating, and upper abdominal pain. These symptoms are similar to those of peptic ulcers and dyspepsia [10].

Most of the polycases were internal disease poly (80.75\%), which is in accordance with the indication that PPI which is related to GI diseases.

\section{Therapy \\ PPI drug classes}

Lansoprazole was the most widely used PPI (76\%) compared with omeprazole (24\%), while rabeprazole, esomeprazole, and pantoprazole were not prescribed (Table 2). Based on information obtained from hospital personnel, lansoprazole and omeprazole were the only PPI provided for the Indonesian Universal Health Coverage patients in Gatot Soebroto Army Hospital. This was in accordance with the National Formulary in 2013 that the PPI included as anti-ulcer agents were lansoprazole and omeprazole [11].

\section{PPI dose regimen}

The most widely administered PPI dose regimen was $30 \mathrm{mg}$ lansoprazole once daily (279 cases; $69.75 \%$ ). Lansoprazole (30 mg) was also administered twice daily in 25 cases (6.25\%). In this study, PPIs were used for two FDA-approved PPI-class drug indications, gastroesophageal reflux disease (GERD) and dyspepsia. This PPI dose regimen corresponded to the regimen listed in the 2014 National Drug Information in Indonesia where $30 \mathrm{mg}$ lansoprazole once daily was recommended as the PPI for dyspepsia [12]. This also corresponded to the dosage of lansoprazole for dyspepsia in the National Institute For Health And Care Excellence Guidance on the management of dyspepsia, where lansoprazole may be administered at a standard dose of $30 \mathrm{mg}$ once daily or at a high dose of $30 \mathrm{mg}$ twice daily [13]. Lansoprazole ( $30 \mathrm{mg}$ ) may also be given for GERD once or twice daily [14]. This dose may be used to treat gastric acidrelated diseases such as GERD, erosive esophagitis, peptic ulcer either associated with NSAID or H. pylori, and dyspepsia $[12,15]$.

In 28 cases, $20 \mathrm{mg}$ omeprazole was given once a day (7.00\%) and twice a day in 68 cases (17.00\%). For dyspepsia, $20 \mathrm{mg}$ omeprazole can be administered once or twice daily [12,13]. For GERD, 20-40 mg omeprazole can be administered once daily or $20 \mathrm{mg}$ can be administered twice daily $[14,15]$. Besides treating dyspepsia and GERD, this $20 \mathrm{mg}$ dose of omeprazole can also be used to treat GI diseases, such as gastric ulcers and duodenal ulcers, H. pylori-related peptic ulcers, heartburn or stomach pain, and erosive esophagitis [12,15].

\section{PPI administration duration}

The administration duration of PPI is $\leq 4$ weeks. This is in accordance with the drug information handbook, whereas the duration of PPI administration for GERD is omeprazole for up to 4 weeks and lansoprazole for up to 8 weeks [15]. According to the Indonesian agency of drug and food supervisory (BPOM), the duration of therapy with omeprazole or lansoprazole for dyspepsia is $2-4$ weeks [12].

Table 1: Patient characteristics

\begin{tabular}{lll}
\hline Characteristics & Quantity & Percentage (\%) \\
\hline $\begin{array}{l}\text { Sex (n=192 patients) } \\
\text { Female }\end{array}$ & 126 & 65.63 \\
$\quad$ Male & 66 & 34.38 \\
Age (years) (n=192 patients) & & \\
$\quad \leq 17$ & 0 & 0.00 \\
$17-25$ & 2 & 1.04 \\
$26-35$ & 2 & 1.04 \\
$36-45$ & 6 & 3.13 \\
$46-55$ & 31 & 6.15 \\
$56-65$ & 62 & 32.39 \\
$>65$ & 89 & 46.35 \\
Main diagnosis (n=400 prescriptions) & \\
Non-insulin-dependent DM & 153 & 38.52 \\
Dyspepsia & 68 & 17.00 \\
Hypertension & 64 & 16.00 \\
Cardiovascular atherosclerosis & 60 & 15.00 \\
Renal failure & 19 & 4.75 \\
GERD & 18 & 4.50 \\
Stroke & 8 & 2.00 \\
Chronic thyroid disease & 6 & 1.50 \\
Chronic ischemia & 4 & 1.00 \\
Department (n=400 prescriptions) & & \\
Internal medicine & 323 & 80.75 \\
Cardiology and vascular medicine & 71 & 17.75 \\
Neurology & 3 & 0.75 \\
Pulmonology & 3 & 0.75 \\
\hline Dits
\end{tabular}

DM: Diabetes mellitus, GERD: Gastroesophageal reflux disease

Table 2: PPI therapy

\begin{tabular}{|c|c|c|}
\hline Therapy & Quantity $(n=400)$ & Percentage (\%) \\
\hline \multicolumn{3}{|l|}{ PPI drug classes } \\
\hline Lansoprazole & 304 & 76.00 \\
\hline Omeprazole & 96 & 24.00 \\
\hline Esomeprazole & 0 & 0.00 \\
\hline Rabeprazole & 0 & 0.00 \\
\hline Pantoprazole & 0 & 0.00 \\
\hline \multicolumn{3}{|l|}{ Dose regimen } \\
\hline \multicolumn{3}{|l|}{ Lansoprazole } \\
\hline $1 \times 30 \mathrm{mg}$ & 279 & 69.75 \\
\hline $2 \times 30 \mathrm{mg}$ & 25 & 6.25 \\
\hline \multicolumn{3}{|l|}{ Omeprazole } \\
\hline $1 \times 20 \mathrm{mg}$ & 28 & 7.00 \\
\hline $2 \times 20 \mathrm{mg}$ & 68 & 17.00 \\
\hline \multicolumn{3}{|c|}{ Administration duration } \\
\hline Lansoprazole ( & & \\
\hline$\leq 4$ & 304 & 76.00 \\
\hline$>4$ & 0 & 0.00 \\
\hline \multicolumn{3}{|c|}{ Omeprazole (week) } \\
\hline$\leq 4$ & 96 & 24.00 \\
\hline$>4$ & 0 & 0.00 \\
\hline
\end{tabular}

PPI: Proton-pump inhibitor 
The rationale for the use of $\mathrm{PPI}$

The result of the accuracy aspect of PPI were assessed from the patients' condition, dosage, and indication, administration duration, and drug selection (Table 3) [7].

Appropriate assessment of patients' condition

Of the 400 therapies with PPI treatment, all the patients met the exact criteria for an appropriate assessment of their condition. None of the patients had liver disorders, and there were no pregnant and breastfeeding patients that received a PPI that was not appropriate for their condition. Physiologically, the body of a pregnant woman will change in anatomy, physiology, and biochemistry as an adaptation to her pregnancy. Almost all the organ systems, including GI system, undergo physiological changes during pregnancy. GI complaints during pregnancy included vomiting, GERD, and constipation. PPI should be given in cases with persistent symptoms or when complications occur.

Omeprazole should not be given during pregnancy because it is category $\mathrm{C}$ drug, which causes teratogenic effects on the fetus, whereas other PPI classes are classified as B [16]. The use of PPI, either omeprazole, lansoprazole, rabeprazole, pantoprazole, or esomeprazole, should also be avoided in breastfeeding women [12].

The consumption of lansoprazole in patients with impaired liver function may lead to significantly decreased clearance and increased the area under the curve (AUC) and half-life of lansoprazole [17]. The use of omeprazole in patients with liver disorders also showed greater bioavailability; however, this does not occur in patients with renal impairment [18]. Due to the risk of drug accumulation in liver cirrhosis patients, special attention was required, and a dosage adjustment was necessary.

\section{Appropriate indication}

Of the 400 PPI therapies at Outpatients Installation of Gatot Soebroto Army Hospital from July to December 2015, 316 treatments (79.00\%) were maintained to be appropriate indications, and the remaining 84 therapies $(21.00 \%)$ were not suitable. From the 84 unsuitable therapies indication of disease, 34 therapies were for non-insulin deficient-(NID-DM) 29 were for cardiovascular atherosclerosis, ten were for hypertension, four were for renal failure, three were for stroke, three were for chronic thyroid problems, and one was for chronic ischemia. No other conditions that occurred in the patients required PPI therapy.

Several studies have shown that DM is a comorbid disease involving upper GI bleeding and is a risk factor for further bleeding. Changes in prostacyclin, which maintains the gastric mucosa, can occur in DM patients and can lead to increased bleeding. In cases related to DM type 2, the use of PPI was intended to overcome it [19].

Many patients had received antiplatelet therapy for various cardiovascular diseases. The use of these drugs causes major adverse events, such as bleeding complications in the GI tract. Aspirin, a standard antiplatelet therapy, was used in the prevention of cardiovascular disease. However, aspirin can still cause intestinal bleeding. In cases of the inappropriateness of cardiovascular disease, 14 cases were receiving aspirin. Over the past few decades, the use of PPI therapy has decreased the incidence of GI bleeding and has been used with aspirin to reduce such bleeding [20].
In cases of the inappropriateness of chronic ischemia, chronic thyroid, and hypertension, aspirin had been prescribed for these diseases. Aspirin works by inhibiting the cyclooxygenase enzyme that functions to convert arachidonic acid into endoperoxides and furthermore to be prostaglandins. Prostaglandins play an essential role in the regulation of $\mathrm{HCl}$ secretion from parietal cells and GI defenses, and thus, destroyed cytoprotection can cause mucosal injury, erosion, and ulcers. The use of PPI in these indications was intended to prevent the side effects of aspirin [21]. In addition, some patients complained of dyspepsia, and GERD and PPI were prescribed to treat them.

\section{Appropriate dosage}

Of the 400 therapies, there were 316 treatments (79.00\%) deemed to have an appropriate dose, and $84(21.00 \%)$ were unsuitable. The dosage of PPI given for dyspepsia varied, $30 \mathrm{mg}$ lansoprazole was prescribed once or twice daily, or $20 \mathrm{mg}$ omeprazole was prescribed once or twice daily. Based on the guidance of the PPI dosage used for dyspepsia, $20 \mathrm{mg}$ omeprazole or $30 \mathrm{mg}$ lansoprazole should only be administered once daily [12]. According to Patel and Dunn, the dosage of PPI used for dyspepsia was appropriate because three different doses of PPI could be used for dyspepsia, with standard, low, or high doses [13]. Standard doses are defined as one dose of $30 \mathrm{mg}$ lansoprazole or $20 \mathrm{mg}$ omeprazole per day, a low dose was $15 \mathrm{mg}$ lansoprazole or $10 \mathrm{mg}$ omeprazole per day, and high doses were lansoprazole $30 \mathrm{mg}$ twice per day or $40 \mathrm{mg}$ omeprazole per day. For the initial symptoms of dyspepsia, patients may take high doses for 4 weeks and then proceeded with low doses if symptoms persist.

The dosage of PPI given for GERD also varied. Patients could be given $30 \mathrm{mg}$ lansoprazole once or twice daily or $20 \mathrm{mg}$ omeprazole once or twice daily. According to Wolfe and Blunton, the dosage of PPI for GERD was appropriate as $30 \mathrm{mg}$ lansoprazole could be administered once or twice a day or $20 \mathrm{mg}$ omeprazole could be given once a day or $40 \mathrm{mg}$ twice a day [14]. Vanderhoff and Tahboub stated that PPI therapy for GERD could be given once or twice daily, and the doses could be reduced in accordance with the patients' response [22].

From our analysis, it could be concluded that all the doses of PPI given for dyspepsia and GERD were appropriate. The inappropriate doses from 84 therapies (21.00) were because of an incorrect diagnosis; therefore, the inappropriate dose of PPI drugs was also ascertained.

\section{Appropriate administration duration}

Of the 400 therapies receiving PPI, 316 (79.00\%) were deemed to have an appropriate administration duration, and the remaining 84 therapies (21.00\%) were inappropriate. The longest duration of PPI administration was 4 weeks and appropriate according to the Drug Information Handbook and Indonesian National Drug Information $[12,15]$. The administration duration of PPI for GERD was omeprazole for up to 4 weeks and lansoprazole up to 8 weeks [15]. According to BPOM, the administration duration of omeprazole and lansoprazole for dyspepsia was 2-4 weeks [12]. According to Durand et al., the maximum recommended PPI treatment for almost all indications is 8 weeks [23]. Vanderhoff and Tahboub stated that the use of omeprazole and lansoprazole for $<12$ weeks is safe [22]. The 86 inappropriate administration duration cases were unsuitable diagnoses, and therefore, the administration duration of PPI was also considered inappropriate.

Table 3: The rational frequency for the use of PPI

\begin{tabular}{|c|c|c|c|c|}
\hline \multirow[t]{2}{*}{ Accuracy aspects } & \multicolumn{2}{|c|}{ Quantity $(n=400)$} & \multicolumn{2}{|c|}{ Percentage (\%) } \\
\hline & Appropriate & Inappropriate & Appropriate & Inappropriate \\
\hline Assessment of patient condition & 400 & 0 & 100.00 & 0.00 \\
\hline Dosage & 316 & 84 & 79.00 & 21.00 \\
\hline Administration duration & 316 & 84 & 79.00 & 21.00 \\
\hline Drug selection & 335 & 65 & 83.75 & 16.25 \\
\hline
\end{tabular}

PPI: Proton-pump inhibitor 
Appropriate drug selection

Of the 400 patients receiving PPI, 335 (83.75\%) were given an appropriate drug selection, and the remaining 65 (16.25\%) were inappropriate. In 22 cases, there were drug interactions between the PPI and other drugs, including the interaction between omeprazole and lansoprazole with clopidogrel. The remaining 33 cases were determined to be inappropriate drug selections because the PPI prescribed was not in accordance with the indication.

Clopidogrel was used as antiplatelet therapy for acute coronary patients and in patients undergoing percutaneous intervention, which has been associated with an increased risk of GI bleeding. PPI has been used with clopidogrel to reduce the risk of GI bleeding. The use of clopidogrel with omeprazole and/or lansoprazole may lead to drug interactions. Clopidogrel is a prodrug that must be activated through the metabolism of CYP450, mainly through isoenzyme CYP2C19, to convert the prodrug to a thiol derivative in its active form. Omeprazole and lansoprazole are metabolized through the same pathway, thus leading to competition between clopidogrel and omeprazole and lansoprazole. This interaction inhibits the change of clopidogrel to its active form which reduces the effectiveness of the therapy [24].

Rabeprazole is primarily metabolized in a non-enzymatic way to be thioether rabeprazole which is a weak inhibitor in CYP2C19 compared with omeprazole; thus, rabeprazole is the PPI that may be used when taken with clopidogrel [25]. Based on other studies, pantoprazole was also recommended as a safer therapy prescribed with clopidogrel compared with other PPI because there were fewer interactions between clopidogrel and pantoprazole [26].

\section{PPI drug interactions}

Drug interactions with PPI were found in 324 prescriptions $(81.00 \%)$ of 400 in 475 cases (Table 4). Major interactions were identified in 42 cases consisting of interactions between lansoprazole and omeprazole with mycophenolate mofetil (MMF), cilostazol, and clopidogrel. Moderate interactions were identified in 138 cases consisting of interactions between lansoprazole and omeprazole with warfarin, iron, propranolol, simvastatin, atorvastatin, and levothyroxine as well as interactions of omeprazole with cyclosporine. Minor interactions were identified in 295 cases consisting of interactions between lansoprazole and omeprazole with sucralfate, antacid, and cyanocobalamin, as well as lansoprazole with theophylline.

\section{Major interactions}

The interaction of MMF with PPI caused a decrease in MMF active metabolite exposure, increasing the risk of failure of MMF, therapy including acute rejection after transplantation. Increased intragastric $\mathrm{pH}$ due to the use of PPI caused a decrease in MMF dissolution resulting in decreased MMF absorption [27]. MMF doses need to be increased to $1.5 \mathrm{~g}$ twice daily to achieve immunosuppressive effects equivalent to standard doses when administered with PPI [28].

Omeprazole and lansoprazole are competitive inhibitors of CYP2C19 metabolism enzymes. The CYP2C19 enzyme is responsible for the metabolism of cilostazol. Therefore, the inhibition of the enzyme by lansoprazole or omeprazole may lead to an increase in the concentration of cilostazol and the potential for an antiplatelet effect from cilostazol. The dose of cilostazol could be reduced if there was evidence of an increase in plasma concentrations of cilostazol during the monitoring of drug plasma concentrations [29]. Clopidogrel undergoes conversion to its active form with the help of the CYP2C19 enzyme. Inhibition of the CYP2C19 enzyme by lansoprazole or omeprazole causes a significant decrease in the $\mathrm{C}_{\max }$ and AUC from the clopidogrel active metabolite. Therefore, the antiplatelet activity of clopidogrel decreases and causes an increased risk of thrombotic events [30]. PPI, such as pantoprazole, can lower the inhibition effect of CYP2C19 [31].

\section{Moderate interactions}

The interaction of warfarin with PPI occurs through the inhibition of CYP2C19 metabolism enzymes competitively by lansoprazole and
Table 4: Identified PPI drug interactions ( $n=475$ cases)

\begin{tabular}{|c|c|c|}
\hline Severity level & Incidence & Percentage (\%) \\
\hline \multicolumn{3}{|l|}{ Major Severity } \\
\hline MMF-Omeprazole & 1 & 0.22 \\
\hline MMF-Lansoprazole & 4 & 0.87 \\
\hline Cilostazol-Omeprazole & 2 & 0.43 \\
\hline Cilostazol-Lansoprazole & 15 & 3.25 \\
\hline Clopidogrel-Omeprazole & 2 & 0.43 \\
\hline Clopidogrel-Lansoprazole & 18 & 3.90 \\
\hline \multicolumn{3}{|l|}{ Moderate Severity } \\
\hline Warfarin-Omeprazole & 1 & 0.22 \\
\hline Warfarin-Lansoprazole & 2 & 0.43 \\
\hline Iron-Omeprazole & 2 & 0.43 \\
\hline Iron-Lansoprazole & 2 & 0.43 \\
\hline Levothyroxine-Omeprazole & 2 & 0.43 \\
\hline Levothyroxine-Lansoprazole & 11 & 2.38 \\
\hline Propranolol-Omeprazole & 3 & 0.65 \\
\hline Propranolol-Lansoprazole & 3 & 0.65 \\
\hline Cyclosporine-Omeprazole & 1 & 0.22 \\
\hline Simvastatin-Omeprazole & 15 & 3.25 \\
\hline Simvastatin-Lansoprazole & 49 & 10.61 \\
\hline Atorvastatin-Omeprazole & 8 & 1.73 \\
\hline Atorvastatin-Lansoprazole & 39 & 8.44 \\
\hline Severity level & Incidence & Percentage (\%) \\
\hline \multicolumn{3}{|l|}{ Minor Severity } \\
\hline Cyanocobalamin-Omeprazole & 25 & 5.41 \\
\hline Cyanocobalamin-Lansoprazole & 73 & 15.80 \\
\hline Sucralfate-Omeprazole & 48 & 10.39 \\
\hline Sucralfate-Lansoprazole & 135 & 29.22 \\
\hline Theophylline-Lansoprazole & 1 & 0.22 \\
\hline Antacid-Omeprazole & 1 & 0.22 \\
\hline Antacid-Lansoprazole & 12 & 2.60 \\
\hline
\end{tabular}

omeprazole, leading to decreased warfarin metabolism, especially R-warfarin. Monitoring the patient's international normalized ratio levels can be done when the combination of the drugs cannot be avoided. Warfarin dose adjustments can be performed when necessary to maintain the expected anticoagulation levels [32]. Similar results have also been found with the combined use of propranolol with lansoprazole or omeprazole [33]. Metabolic inhibition leads to increased propranolol exposure and toxicity. When propranolol is used in conjunction with omeprazole or lansoprazole, it is necessary to measure propranolol toxic effects, such as bradycardia and hypotension, in patients [33].

An increased intragastric $\mathrm{pH}$ due to the use of PPI caused a decrease in levothyroxine absorption, resulting in a decrease in efficacy characterized by increased thyroid-stimulating hormone (TSH) levels of patients. The strict monitoring of TSH levels and levothyroxine dose adjustments is necessary for patients receiving levothyroxine therapy with PPI [34]. Increased intragastric pH also affects iron absorption rates, leading to a decrease in iron bioavailability. Patients with an iron deficiency who are given PPI therapy may be treated with high-dose iron therapy for longer periods or with intravenous iron therapy [35].

PPIs, such as lansoprazole and omeprazole, are competitive inhibitors of P-glycoprotein efflux transporters. The combined use of omeprazole or lansoprazole with a P-glycoprotein transporter substrate, such as statin drugs, may decrease the drug secretion to the intestinal lumen, so the bioavailability of simvastatin or atorvastatin increases. This leads to an increased risk of drug toxicity such as myalgia, myositis, myopathy, or rhabdomyolysis. If the patient received statin drug therapy with PPI, monitoring of these toxic effects should be undertaken [36-39].

The combined use of cyclosporine with omeprazole showed interactions in the cyclosporine metabolic stage; however, the interaction effect on cyclosporine concentrations remains unclear. In one case review, both increased and decreased levels of cyclosporine had been found. Monitoring cyclosporine concentrations in the blood 
may be performed in patients receiving therapy with cyclosporine and omeprazole. Adjustments to cyclosporine doses may also be performed when necessary $[40,41]$.

\section{Minor interactions}

The interaction between PPI and cyanocobalamin is minor, where the effect of this interaction was the decrease in cyanocobalamin absorption caused by increased intragastric pH during PPI therapy. Possible management of this interaction include replacing the anti-ulcer therapy with ranitidine, famotidine, or sucralfate, providing that they are taken about $2 \mathrm{~h}$ apart, or cyanocobalamin is administered intramuscularly or subcutaneously [42].

Sucralfate leads to an increased secretion of mucus-rich bicarbonate ions and provides buffer effects in the mucosal region. This leads to decreased protonation and conversion of PPI into its active form, thereby reducing the effectiveness of PPI. This interaction could be prevented by giving PPI $1 \mathrm{~h}$ before sucralfate. Similar interactions were also found in the combined use of PPI and antacids [43]

Interactions with minor severity subsequently occurred between theophylline and lansoprazole, which caused a decrease in serum theophylline concentrations. The interaction occurred through the induction of theophylline metabolism enzyme CYP1A2 by lansoprazole, which caused an increase in theophylline clearance. Management could be done through monitoring the serum concentrations of theophylline and adjusting the theophylline dose when necessary [44].

\section{CONCLUSION}

Based on this study, the use of PPI in patients at the Outpatient Installation Gatot Soebroto Army Hospital from July to December 2015 was not completely appropriate and had great potential for interactions with other drugs.

\section{CONFLICTS OF INTEREST}

The authors have no conflicts of interest.

\section{REFERENCES}

1. Atkins AM, Sekar MC. Proton pump inhibitors: Their misuse, overuse, and abuse. IOSR J Pharm 2013;3:25-9.

2. Ding J, Heller DA, Ahern FM, Brown TV. The relationship between proton pump inhibitor adherence and fracture risk in the elderly. Calcif Tissue Int 2014;94:597-607.

3. Sheen E, Triadafilopoulos G. Adverse effects of long-term proton pump inhibitor therapy. Dig Dis Sci 2011;56:931-50.

4. van der Hoorn MM, Tett SE, de Vries OJ, Dobson AJ, Peeters GM. The effect of dose and type of proton pump inhibitor use on risk of fractures and osteoporosis treatment in older Australian women: A prospective cohort study. Bone 2015;81:675-82.

5. Setiawati A. Drug interaction. In: Gunawan SG, Setiabudy R, Elysabeth N, editor. Pharmacology and Therapy. $5^{\text {th }}$ ed. Jakarta: Balai Penerbit FKUI; 2007. p. 862-85.

6. Tatro DS, editor. Drug Interaction Facts. California: Missouri; 2001

7. Nasution NK. The Relationship of Diet with the Incidence of Dyspepsia Syndrome to Student at Faculty of Public Health Universitas Sumatera Utara in 2015. Medan: Faculty of Public Health, Universitas Sumatera Utara; 2016.

8. Pilotto A, Franceschi M. Helicobacter pylori infection in older people. World J Gastroenterol 2014;20:6364-73.

9. Ajarallah BD. Management of diabetic gastroparesis. Saudi J Gastroenterol 2011;17:97-104

10. Camilleri M, Parkman HP, Shafi MA, Abell TL, Gerson L, American College of Gastroenterology, et al. Clinical guideline: Management of gastroparesis. Am J Gastroenterol 2013;108:18-37.

11. Ministry of Health of the Republic Indonesia. Formularium National, Number HK.02.02/MENKES/523/2015. Jakarta: Ministry of Health, Republic Indonesia; 2013.

12. Indonesian Agency of Drug and Food Supervisory. Indonesian National Drug Information. Jakarta: Sagung Seto; 2014.

13. Patel K, Dunn J. Updated NICE guidance on the management of dyspepsia. Prescriber 2015;26:5-6.
14. Wolfe MM, Blanton WP. Proton Pump Inhibitor in Pocket Guide to Gastrointestinal Drugs. London: Wiley Blackwell; 2014.

15. Lacy CF, Armstrong LL, Goldman MP, Lance LL. Drug Information Handbook with International Trade Names Index. Ohio: Lexicomp; 2009.

16. Firmansyah MA. Management of gastrointestinal disorders in pregnancy. Medicinus 2014;27:46-51.

17. Landes BD, Petite JP, Flouvat B. Clinical pharmacokinetics of lansoprazole. Clin Pharmacokinet 1995;28:458-70.

18. Sweetman SC, editor. Martindale-the Complete Drug Reference. London: Pharmaceutical Press; 2009.

19. Ika PD. Influential Factors against Upper Gastrointestinal Changes to Patients with Coronary Heart Disease with Antiplatelet Therapy. Semarang: Universitas Diponegoro; 2013.

20. Pipilis A, Makrygiannis S, Chrisanthopoulou E, Sourlas N, Kaliambakos S, Ntailianas P, et al. Gastrointestinal bleeding in patients receiving antiplatelet and anticoagulant therapy: Practical guidance for restarting therapy and avoiding recurrences. Hellenic J Cardiol 2014:55:499-509.

21. Vella V. Drug-induced peptic ulcer disease. J Malta Coll Pharm Pract 2005:10:15-9.

22. Vanderhoff BT, Tahboub RM. Proton pump inhibitors: An update. Am Fam Physician 2002;66:273-80.

23. Durand C, Willett KC, Desilets AR. Proton pump inhibitor use in hospitalized patients: Is overutilization becoming a problem? Clin Med Insights Gastroenterol 2012;5:65-76

24. Mohammad A, Brilakis ES, Weideman RA, Little BB, Banerjee S. The clinical relevance of the clopidogrel-proton pump inhibitor interaction. J Cardiovasc Trans Res 2012;5:547-52.

25. Funck-Brentano C, Szymezak J, Steichen O, Ducint D, Molimard M, Remones $\mathrm{V}$, et al. Effects of rabeprazole on the antiplatelet effects and pharmacokinetics of clopidogrel in healthy volunteers. Arch Cardiovasc Dis 2013; 106:661-71.

26. Ferreiro JL, Ueno M, Tomasello SD, Capodanno D, Desai B, Dharmashankar K, et al. Pharmacodynamic evaluation of pantoprazole therapy on clopidogrel effects: Results of a prospective, randomized, crossover study. Circ Cardiovasc Interv 2011;4:273-9.

27. Kees MG, Steinke T, Moritz S, Rupprecht K, Paulus EM, Kees F, et al. Omeprazole impairs the absorption of mycophenolate mofetil but not of enteric-coated mycophenolate sodium in healthy volunteers. J Clin Pharmacol 2012;52:1265-72

28. Kofler S, Shvets N, Bigdeli AK, König MA, Kaczmarek P, Deutsch MA, et al. Proton pump inhibitors reduce mycophenolate exposure in heart transplant recipients-a prospective case-controlled study. Am J Transplant 2009:9:1650-6

29. Suri A, Bramer SL. Effect of omeprazole on the metabolism of cilostazol. Clin Pharmacokinet 1999;37 Suppl 2:53-9.

30. Indonesian Agency of Drug and Food Supervisory. Buletin Berita MESO. Jakarta: BPOM; 2009

31. Angiolillo DJ, Gibson CM, Cheng S, Ollier C, Nicolas O, Bergougnan L, et al. Differential effects of omeprazole and pantoprazole on the pharmacodynamics and pharmacokinetics of clopidogrel in healthy subjects: Randomized, placebo-controlled, crossover comparison studies. Clin Pharmacol Ther 2011;89:65-74.

32. Sutfin T, Balmer K, Boström H, Eriksson S, Höglund P, Paulsen O, et al. Stereoselective interaction of omeprazole with warfarin in healthy men. Ther Drug Monit 1989;11:176-84.

33. Lacobellis G, editor. Drug-drug Interaction in the Metabolic Syndrome. New York: Nova Publisher; 2006.

34. Sachmechi I, Reich DM, Aninyei M, Wibowo F, Gupta G, Kim PJ, et al. Effect of proton pump inhibitors on serum thyroid-stimulating hormone level in euthyroid patients treated with levothyroxine for hypothyroidism. Endocr Pract 2007;13:345-9.

35. Ajmera AV, Shastri GS, Gajera MJ, Judge TA. Suboptimal response to ferrous sulfate in iron-deficient patients taking omeprazole. Am J Ther 2012;19:185-9

36. Singh S, Choudhary N, Rai J, Siddiqui I, Sharma S. A validated RPUPLC method development for simultaneous estimation of lansoprazole and naproxen in bulk and tablet dosage from. Asian J Pharm Clin Res 2013;6:150-2

37. Bhargav K, Venkata SB, Venkata SK, Himaja G, Samuel GG, Bhaskar RK. Pharmacokinetic drug interaction between clopidogrel and esomeprazole in adult healthy male volunteers. Asian J Pharm Clin Res 2017;10:336-41.

38. Salunkhe PS. Formulation and evaluation of gastroretentive tablets of antiulcer drug. Asian J Pharm Clin Res 2016;9:48-52.

39. Sipe BE, Jones RJ, Bokhart GH. Rhabdomyolysis causing AV blockade due to possible atorvastatin, esomeprazole, and clarithromycin interaction. Ann Pharmacother 2003;37:808-11. 
40. Schouler L, Dumas F, Couzigou P, Janvier G, Winnock S, Saric J. Omeprazol-cyclosporin interaction. Am J Gastroenterol 1991;86:1097.

41. Arranz R, Yañez E, Franceschi JL, Fernández-Rañada JM. More about omeprazole-cyclosporine interaction. Am J Gastroenterol 1993;88:154-5.

42. Marcuard SP, Albernaz L, Khazanie PG. Omeprazole therapy causes malabsorption of cyanocobalamin (vitamin B12). Ann Intern Med
1994;120:211-5.

43. Wedemeyer RS, Blume H. Pharmacokinetic drug interaction profiles of proton pump inhibitors: An update. Drug Saf 2014;37:201-11.

44. Granneman GR, Karol MD, Locke CS, Cavanaugh JH. Pharmacokinetic interaction between lansoprazole and theophylline. Ther Drug Monit 1995; 17:460-4. 